\title{
Participatory Research Engagement of Vulnerable Populations: Employing Survivor-Centered, Trauma-Informed Approaches
}

\author{
Selima N. Jumarali ${ }^{1}$ (D, Nkiru Nnawulezi ${ }^{1}$ (D), Samantha Royson ${ }^{1}$ (D, Carrie Lippy ${ }^{2}$ (D) Ashley N. Rivera ${ }^{1}$ (D, Ty Toopet ${ }^{1}$ (D) \\ ${ }^{1}$ University of Maryland Baltimore County, ${ }^{2}$ National Resource Center on Domestic Violence \\ Keywords: participatory engagement, community-based, intimate partner violence, survivor-centered, domestic violence, trauma-informed \\ https://doi.org/10.35844/001c.24414
}

Journal of Participatory Research Methods

Vol. 2, Issue 2, 2021

\begin{abstract}
Participatory research methods increase the quality and relevance of a study and are a key element of community practice. However, participatory methods can be difficult to employ at the outset of a research study with vulnerable, hard-to-reach populations. Intimate partner violence survivors are a particularly vulnerable population who are at increased risk of experiencing abuse-related trauma and have distinct safety-related needs. In order to engage survivor populations, researchers can employ survivor-centered, trauma-informed approaches to build trust and develop relationships that facilitate increased engagement in the research process over time. This paper outlines the methods and strategies that academic partners used to establish, increase, and maintain participatory engagement with women who experienced harm by intimate partners. The process began with a community-based, qualitative needs assessment study for survivors whose partners were in a relationship violence intervention program. In addition to responding to specific aims, this study simultaneously helped to create a pool of potential collaborators. Academic partners used member checking to establish trustworthiness of the study findings and introduce the participants to the concepts of participatory engagement. Next, researchers established an advisory group to develop practice recommendations, which ultimately led to academic and community partners co-designing a communitybased dissemination project. We discuss successes and tensions inherent in the engagement process, important lessons learned, and provide recommendations for future community practice.
\end{abstract}

Participatory approaches involve meaningful engagement of community stakeholders in the research process (Nnawulezi et al., 2018; Vaughn \& Jacquez, 2020). Researchers must determine what methods to employ to arrive at the intended level of participation from community stakeholders (Chung \& Lounsbury, 2006; Vaughn \& Jacquez, 2020). Participatory approaches centralize sharing power and collaborative decision-making between community partners and academic partners throughout the research process, from conceptualization to analysis to dissemination of study findings (Israel et al., 2008; Ragavan et al., 2020). In traditional community-based participatory research (CBPR), academic partners approach community partners - and sometimes, but less often, vice versa - to establish a connection around conducting research on a topic of shared interest (Duran et al., 2012). However, approaching community partners to initiate a CBPR project can be challenging when the population of interest experiences numerous vulnerabilities due to their social positionalities and access to material resources, thereby making them potentially hard-to-reach. 
Survivors of intimate partner violence (IPV) are considered vulnerable because their partners use abuse to acquire and maintain coercive control over them (Stark, 2007). IPV includes physical abuse, sexual violence, emotional abuse, psychological aggression, and/or stalking, and experiencing this violence has been associated with adverse physical and mental health outcomes (Dillon et al., 2013; Smith et al., 2018). Thus, IPV survivors have distinct needs as it relates to safety and their experiences of abuse-related trauma (Andrews et al., 2019; Goodman et al., 2016). For instance, IPV survivors may be hesitant to openly discuss their experiences of abuse, particularly if they are still with their abusive partners (Kubiak et al., 2012). When working with survivors of violence and other forms of trauma, researchers can benefit from tailoring their approaches to meeting survivors' unique needs (Wilson et al., 2015). The purpose of this paper is to describe the strategies employed to establish and sustain ongoing participatory engagement of hard-to-reach IPV survivors.

\section{Survivor-Centered \& Trauma-Informed Approaches for Survivors}

Survivor-centered approaches acknowledge that IPV survivors know their situations and needs best, which vary based on their identities and contexts. Survivor-centered practices centralize survivors' autonomy and require that researchers and practitioners collaborate with survivors to understand their unique needs, contexts, and means of coping in order to provide relevant information for survivors to make their own informed choices (Nichols, 2013). Research has demonstrated the benefits of implementing survivor-centered practices, including survivors' increased satisfaction with systems, fewer depressive symptoms, and greater quality of life over time (Bennett Cattaneo \& Goodman, 2010). Survivors have also been found to feel more optimistic about support acquired through community resources that are tailored to their individual goals (Goodman et al., 2016).

Trauma-informed care is a strengths-based approach that considers the needs of the survivor as a whole person. In the context of domestic violence, traumainformed approaches encompass six key practices: 1) promoting emotional safety for survivors; 2) restoring their choice and control; 3) facilitating connection amongst survivors; 4) supporting and enhancing their methods of coping; 5) responding to survivors' identities and contexts including systems of oppression and marginalization; and 6) building upon their strengths (Goodman et al., 2016; Wilson et al., 2015). Implementing these practices requires creating a safe, welcoming environment in which survivors can share their stories and build authentic relationships with practitioners and with one another (Menschner \& Maul, 2016; Wilson et al., 2015). Trauma-informed care involves identifying survivors' strengths, prioritizing their autonomy, and considering how identity and context influence survivors' experiences and needs (Menschner \& Maul, 2016; Substance Abuse and Mental Health Services Administration, 2014; Wilson et al., 2015). Lastly, trauma-informed care involves sharing power through collaborative decision-making, as well as developing opportunities for survivors to contribute and cultivate their skills to guide practice (Wilson et al., 2015). 


\section{Survivor-Centered, Trauma-Informed Community-Based Participatory Research}

Survivor-centered and trauma-informed approaches align with the implementation of community-based participatory research (CBPR) principles because of the overlapping prioritization of sharing power and working in equitable partnership, as well as centering affected communities and responding to their unique needs and contexts (Goodman et al., 2017; Nichols, 2013). Specifically, CBPR requires studies be conducted within an authentic partnership in a way that is responsive and facilitates bidirectional learning between academic and community partners (Collins et al., 2018; Goodman et al., 2017; Israel et al., 2008). In addition, CBPR emphasizes the expertise, and reflects the goals, of the community (Collins et al., 2018). Survivor-centered approaches similarly prioritize working in partnership with survivors, being flexible and responsive to survivors' needs, and cultivating opportunities for advocates to learn from survivors (Nichols, 2013). Survivor-centered and trauma-informed approaches also emphasize survivors' goals and expertise on their lived experiences and are responsive to survivors' distinct needs and varying contexts (Wilson et al., 2015). CBPR is dependent on the strengths of the community partners, just as trauma-informed strategies build upon survivors' strengths (Collins et al., 2018; Goodman et al., 2017; Israel et al., 2008).

Trust is a shared core element of relationship development and maintenance across CBPR and survivor-centered and trauma-informed approaches (Goodman et al., 2017; Lucero et al., 2020). Within CBPR approaches, building trust with community partners requires that academic partners be open and engaging, though this stance alone is not enough to acquire trust (Collins et al., 2018). Academic partners must first understand the historical context of the research they are conducting (Christopher et al., 2008). Academic partners must also demonstrate respect for community partners by taking a strengths-based perspective of the community rather than a deficitoriented perspective (Duran et al., 2012). Trust building in CBPR requires that academic partners be present in the community, listen to community partners, and "show up" consistently for communities beyond research efforts, such as by attending community events and activities (Christopher et al., 2008; Collins et al., 2018; D’Alonzo, 2010; Goodman et al., 2017). Team-building exercises during meetings amongst academic and community partners can promote trust-building and serve to build relationships (Collins et al., 2018). Survivorcentered and trauma-informed approaches can guide these trust-building practices by emphasizing a strengths-based approach and prioritizing survivors' needs and goals even when they do not directly overlap with the research process (D’Alonzo, 2010; Goodman et al., 2017).

\section{Overview of the Research Process}

This paper describes the participatory strategies academic partners used to increase engagement of participants from a study on the needs of IPV survivors whose partners participated in a relationship violence intervention program. 
This subpopulation of survivors is particularly vulnerable and hard-to-reach because they may not be actively help-seeking or participating in domestic violence services (Nnawulezi \& Murphy, 2019). In order to recruit study participants, academic partners collaborated with a local relationship violence intervention program who routinely reached out to survivor-partners of abusive partners in the program. Academic partners worked with program therapists to obtain contact information for the survivor-partners of those receiving treatment from the program. The academic partners called and sent letters to invite 152 survivors to participate in confidential, individual interviews. Of those, 67 people answered the invitations, and 24 women were interviewed over the phone or in person. Using a semi-structured interview guide, academic partners asked survivors about their needs, their help-seeking strategies, the effectiveness of the resources they used and the relationship violence intervention program, and what resources should be available for survivors in similar situations. Academic partners analyzed the data using open thematic analysis, which involves coding the data inductively to arrive at themes that tell a compelling story in response to the research question (Braun et al., 2019; Miles, M. B., Huberman, A. M., \& Saldaña, J., 2014).

\section{Member Checking}

Academic partners invited all 24 participants to attend one of two membercheck sessions. Member checking is a process used to enhance the trustworthiness of qualitative research - the equivalent of validity testing in quantitative designs (Creswell \& Miller, 2000; Lincoln \& Guba, 1985). Member checking involves incorporating feedback from study participants on preliminary study findings as part of the data analytic process. Member checks can take many forms, including participants reviewing their transcripts, individual interviews, or focus groups (Birt et al., 2016). Academic partners held two member check focus groups, which were attended by a total of five study participants.

\section{Advisory Group}

Academic partners invited the women who participated in the member check sessions to participate in an advisory group to develop recommendations based on study findings and contribute to community change. Over the course of approximately four meetings facilitated by academic partners, the academic partners and the women who experienced harm went through the Expectations to Change process, an interactive workshop-based method to engage participants with study findings by setting expectations for the process, reviewing findings, identifying and interpreting key findings, making recommendations, and planning for change (Adams et al., 2015). The group collectively identified key findings, established recommendations to respond to these findings, and brainstormed how these recommendations could be implemented (Adams et al., 2015). 
At this point in the process, the two women began transitioning from former participants to community partners. They developed trust for the academic partners and expressed a desire to continue meeting - despite the principal investigator's (PI) lack of resources to continue paying them once the Expectations to Change process was complete. This led to the current iteration of the advisory group. Subsequent meetings evolved such that academic and community partners continued to meet and collaboratively generate ideas about how the recommendations could be implemented. Initially, the group worked to co-create and adapt a community-based advocacy intervention for people who experience harm, referenced in the academic literature as survivors, when their partners enter a relationship violence intervention program (Sullivan \& Bybee, 1999). Over time, the priorities of the advisory group have shifted toward a community-based dissemination project that involves sharing findings from the study with the community at large via a podcast. Thus, the community partners were engaged initially to ensure data validity, but subsequently became involved in data analysis and interpretation and eventually in the collaborative development of a community-based dissemination project. In this paper, we use "academic partners" to reference authors who participated in conducting the needs-assessment study and reference the authors who participated in the study as "those who experienced harm" or describe them as "community partners."

\section{Participatory Engagement: Strategies and Tensions}

In this paper, we describe strategies that academic partners used to increase engagement of people who experienced harm by intimate partners throughout the arc of the research, focusing particularly on the advisory group process. As outlined in the literature above, increasing opportunities for participants to contribute to the design and implementation of research greatly strengthens and grounds the research (Wallerstein \& Duran, 2017). The literature also outlines that to do this effectively and responsively for IPV survivors and other vulnerable populations, the participatory approaches must be survivorcentered and trauma-informed (Ghanbarpour et al., 2018).

In this section, we give concrete examples of the strategies academic partners used and the tensions that emerged in our efforts to increase participation of people who experienced harm by intimate partners. We organize these strategies and tensions by four overlapping principles between survivorcentered, trauma-informed, and CBPR approaches. These include: 1) Being responsive to the unique needs and contexts of those who have experienced harm; 2) Building trust and authentic relationships; 3) Shifting and sharing power; and 4) Bidirectional learning. 


\section{Principle 1: Being Responsive to the Unique Needs and Contexts of Those Who Have Experienced Harm}

\section{Flexible and Responsive Meetings}

How academic partners enter into a relationship with community partners is a critical opportunity to set the tone for the development of continued partnership by demonstrating flexibility and responsiveness to participants' needs and prioritizing participants' safety and autonomy - particularly when participants are IPV survivors (Andrews et al., 2019; Goodman et al., 2017). During study recruitment, academic partners collected participants' preferences for method and timing of being contacted to consider their needs and prioritize their safety. From that point forward, academic partners continued to communicate with participants using their preferred methods of contact, offered snacks and childcare at all meetings, distributed compensation at the beginning of each session, and provided participants with the option of varying their participation based on their comfort and availability. At the start of the member check sessions, academic partners informed participants of established safety measures, provided the location address, and invited them to share if they had any specific safety-related needs. When setting up the space, academic partners ensured that the exits were easily accessible. For the Expectations to Change process, community partners were encouraged to attend meetings even if they could not stay for the entire duration (Adams et al., 2015). They were similarly invited to participate in any number of advisory group meetings even if they could not attend prior or subsequent meetings. Academic partners built in time for attendees to arrive later than the established start time and were prepared for sessions to run beyond the established end time.

In the initial advisory group meetings, academic partners asked participants how they wanted to refer to themselves and those who caused them harm. While academic partners shared that "survivors" is a common term used in the literature, participants explicitly stated that they did not want to be called "survivors." Instead, they preferred to be referred to as people who experienced harm and to their current or former partners as those who have caused harm. This was an opportunity for the academic partners to demonstrate flexibility and follow the lead of the community partners instead of prioritizing academic terminology.

\section{Trauma-Informed Facilitation Techniques}

Understanding trauma and how it may influence participants' needs throughout the entire research process is also imperative when working with IPV survivors (Andrews et al., 2019; Wilson et al., 2015). All interviewers received training in trauma-informed, feminist practices that included regularly checking in with participants about how they felt and if they needed breaks or other supports (Brooks \& Hesse-Biber, 2007; Menschner \& Maul, 2016). Participants were told they could participate as much or as little as they felt 
comfortable with and were reminded that it was always an option to stop participating or leave the space. Participants could also skip or pass on questions or activities without being questioned.

During the member check sessions, academic partners provided handouts with data statements that were short and easily comprehensible. All statements were grouped into categories to ensure that participants reviewed related statements at one time. The sentence structure and emphasis on categorization was intentional to support ease of interpretation, which is a type of traumainformed approach. Because trauma may impact survivors' cognitive functioning, presenting information in concise and clearly defined ways, as compared to complex and long sentences or lists with no defined order or categorization, can be helpful (Billoux et al., 2016).

During the Expectations to Change process, academic partners provided an overview of the session and hung the written agenda on flip chart paper so that participants felt a sense of control over what was happening and when. Academic partners provided information in varying formats (e.g., hanging flip charts, printed handouts, etc.) to cater to varied learning styles and respond to participants' individual needs. Academic partners also read aloud any information presented in written form, again to be inclusive of different levels of literacy, learning styles, and accessibility needs (Macy et al., 2010). These practices centralized participants' emotional safety and their agency in how and to what degree they participated, as well as aimed to be responsive to their varied accessibility needs and contexts (Nichols, 2013; Wilson et al., 2015).

The academic partners balanced structure and flexibility in facilitation of the Expectations to Change process by capitalizing on community partners' differing strengths and accommodating their varying styles and needs (Adams et al., 2015). Academic partners participated in breakout groups with community partners to collaboratively develop recommendations; a more structured community partner worked with a more directive academic partner, and a more flexible and spontaneous community partner with a less directive academic partner. This approach was collaborative and considered the unique needs and strengths of those who had experienced harm. In addition, when reviewing the data statements to identify key findings, those who had experienced harm expressed a desire to see the raw data and additional context for the statements. Academic partners then mobilized to gather excerpts that corresponded to each data statement and brought that to the following meeting. In turn, those who experienced harm expressed a greater connection to, and understanding of, the data statements, and were more prepared to establish which findings to focus on moving forward.

\section{Asking for Feedback}

To create additional pathways for community partners to provide feedback during the Expectations to Change process, and to ensure that the meetings were productive, academic partners solicited feedback through an evaluation form at the end of each meeting to ask community partners how meetings could be improved, what they liked about each meeting, and whether they 
planned to attend the following meeting (Adams et al., 2015). Through these forms, community partners recommended regularly scheduled breaks and specific snack requests, which academic partners incorporated into the following sessions. The responsiveness of academic partners illustrated a commitment to meeting the needs of those who had experienced harm, which in turn enhanced their engagement and increased their ownership over the process.

As of November 2020, advisory group meetings have continued for a year and a half since the completion of the Expectations to Change process. As a group, we regularly engage in process check-ins and assess each member's interest and capacity in continuing to participate with the group. We also ask if there is anything that members need or want, including shifts in group structure and function. These check-ins have led to the development of a group dynamic of flexibility and adaptability. The group consistently makes space for people to share any personal concerns that may be influencing how they are showing up in the group and what they may individually need to participate. The co-creation of a space that enables members to name what they need alongside regular, active check-ins facilitates responsiveness to the needs and contexts of those who have experienced harm.

\section{Tensions in Being Responsive and Meeting the Needs of Those Who Have Experienced Harm}

We encountered several tensions in being responsive to the needs of people who have experienced harm throughout the research process.

Promoting Open Dialogue and Critical Consciousness. When facilitating the Expectations to Change process, academic partners worked to create an open space where everyone could share their opinions honestly, but they struggled with also valuing the promotion of critical consciousness and maintaining an inclusive space. For instance, when participants were discussing their perspectives on how police deal with domestic violence situations, one participant critiqued police bias and abusive behavior and another asserted that police are doing what they can and that civilians also bring bias to interacting with police. Academic partners validated both participants' experiences and contextualized them based on each of their experiences with, and connections to, police. However, academic partners also struggled with whether and when to provide information about the connections between individual experiences and structural realities that are informed by systems of oppression. In this instance, academic partners chose to share how structural inequities such as racism shaped their perspectives about the police.

Language and Terminology. When preparing this manuscript, the advisory group had an explicit discussion of what language to use in the paper. Community partners re-affirmed their desire to be referred to using "those who have experienced harm." They expressed that the term "survivor" feels like it is simply a rebranding of the term "victim" and asserted that they do not see themselves as survivors nor identify with the term. They simultaneously acknowledged that it may be "clunky" to use the entire phrase throughout the 
paper. Academic partners experienced a tension around how to honor these experiences while also acknowledging the advocacy of previous scholars and community activists that led to the term "survivor," as well as being able to situate this paper within the IPV literature. Academic partners asked clarifying questions about other members' needs and preferences - specifically whether they felt the term "survivor" should not be used for them or for anyone. Those who have experienced harm stated that using the term "survivor" makes sense when talking about the research study and that the terminology of "people who experience harm" should be used when talking about them as individuals and about the group because that is where it becomes "personal." Collectively, we agreed to use the term "survivors" when summarizing previous literature and discussing the original study but otherwise employed the terminology of people who have experienced harm, which is used interchangeably with "community partners," another term the advisory group members agreed to use.

Explicit and Continued Attention to Exposure. When the advisory group was established, it did not have a dissemination plan and thus could not have anticipated community partners' specific concerns about risk of exposure. As the advisory group moved towards planning a podcast and documenting and sharing our process via academic conferences and manuscripts, we have confronted tensions around exposure, specifically for community partners. Community partners have different levels of comfort and interest in being "outed" as people who have experienced harm, particularly if they are still with their partners. We have discussed at length the ways in which community partners could be exposed and have brainstormed strategies for involvement that minimizes their exposure. For instance, we have considered using pseudonyms for authorship and delineated the various contributions that can be made in the visioning, planning, and development of dissemination projects without necessarily being involved in the community-facing aspects of implementation.

Create Regular Feedback Loops. Relatedly, community partners with exposure concerns may find themselves in the minority when participating in an advisory group setting. In our group, this dynamic made it difficult for one of the community partners to raise exposure-related concerns. Upon further discussion, the community partner recommended that the group reinstate collecting formal feedback to allow members to evaluate their meeting experience. Making space for reflection embodies trauma-informed approaches and creates space for members to consider how aligned they feel with the group's process and direction, as well as how they feel about their safety and exposure. The community partner who raised these concerns has led the development of a tool to collect ongoing feedback.

\section{Principle 2: Building Trust and Authentic Relationships}

Academic partners' engagement in survivor-centered and trauma-informed practice supported the development of trust and authentic relationships, which were central to community partners' sustained participation and 
continued investment in the group. In addition to the trauma-informed facilitation techniques outlined above, academic partners employed several additional strategies at the outset to build trust and authentic relationships. For example, the academic partner who conducted interviews also recruited participants to the member check focus group sessions and the subsequent advisory group meetings. This facilitated continuity in the relationship, maintained the connection developed through the interviews, and increased comfort for some community partners to participate based on their familiarity with the academic partner.

Academic partners also incorporated time into each session of the Expectations to Change process for each person to "check in" and share how they were doing, creating an opportunity for fostering connection and building authentic relationships among advisory board members (Adams et al., 2015). Check-ins also provided an opportunity for academic partners to self-disclose more than was possible when interviewing participants during the study or facilitating member check sessions. In addition, academic partners worked to cultivate connection and trust by spending breaks fully present with the group, rather than being on email or otherwise occupied. This practice created space for spontaneous, informal, and personal conversations that also supported relationship-building (Andrews et al., 2019). For example, during one break, the group launched into a conversation about Western astrology and each person's zodiac signs. This conversation shifted the dynamic after the break, enabling a deeper level of vulnerability in the sharing that was not previously present.

As the advisory group has evolved beyond the Expectations to Change process, check-ins have provided space for the group to share important developments in their lives and receive support from the group, thus prioritizing the needs and goals of those who have experienced harm, regardless of whether they directly overlapped with the research process (Adams et al., 2015; Andrews et al., 2019; D’Alonzo, 2010). The continued relationshipbuilding over time has facilitated a deep-seated sense of trust amongst the group. The group established a group text-chat that is not specifically for advisory group-related purposes. This trust-building process has also been facilitated by transparency; academic partners have been honest about this being the first time they are engaging in a participatory process in this way. Community partners assert that they have "grace" for the process and trust academic partners to share what is relevant as it comes up.

We also recognize that our relationship- and trust-building may also have been facilitated by our shared social identities as a group of cisgender women (Muhammad et al., 2015). Specifically, due to transition in some academic partners over time, we are now a group of cisgender women of color. We have openly talked about experiences of sexism and racism and found resonance and support in one another. Similarly, Ragavan and colleagues (2020) conducted 
a systematic review of CBPR studies exploring the experiences of survivors of color and found that people of color who have experienced harm prefer to work with service providers who share their racial and ethnic identities.

\section{Tensions in Building Trust and Authentic Relationships}

Power Differences Across Roles. Some of the tensions we have encountered in building trust and authentic relationships include how to negotiate power dynamics when differences in perspective, opinions, and experiences arise. Despite our shared multiple identities as women of color, academic partners hold privilege and power based on their academic affiliations, the privileges associated with their educational backgrounds (Muhammad et al., 2015), and other marginalized social identities that community partners do not share. Thus, academic partners remain vigilant of group dynamics to ensure that their perspectives do not become the default or "correct" stance on an issue; instead, all group members work to make space for others to contribute and actively solicit other members' perspectives and experiences to inform the discussion. Similarly, it can be difficult for community partners to raise concerns about the group content or process during meetings, particularly when those concerns are not shared by other members of the group. Thus, formal feedback loops can provide an outlet to assist with sharing concerns outside of group meetings and ensuring that all members' concerns are heard and addressed.

Balancing Content with Connection. In addition, balancing time during meetings for developing content as well as relationship-building can become tricky. While the group has erred on the side of making space for relationshipbuilding, some members of the group - both from the academic partners as well as community partners - have experienced tension of not progressing to where we had originally intended, such as implementing the communitybased advocacy intervention and seeking funding for its implementation. This tension is reflected in the CBPR literature. For instance, Duran and colleagues (2012) assert that relationship-building is time-intensive, which can be challenging because time functions differently for academic and community partners. The former is dictated by grant deadlines and tenure clocks, whereas the latter may prioritize acquiring results and disseminating findings.

\section{Principle 3: Shifting and Sharing Power}

Our efforts to shift power dynamics occurred throughout the research process in both big and small ways. For example, implementing member checks can be a mechanism to shift power dynamics between researchers and participants. When researchers acknowledge how their subjective bias may shape their interpretation of research findings and create an opportunity for participants to contribute to interpretation, they create an opportunity to "reverse the research power hierarchy" (Caretta, 2016, p. 311). For example, based on the feedback they received, the academic partners revisited the data and expanded their analyses to explore in greater depth points that participants raised in the member check sessions. Thus, the member check process shaped 
the findings of the needs-assessment study and facilitated the beginning of a shift in power dynamics to increase participants' ownership over the study findings (Caretta, 2016).

Academic partners also worked to shift the power dynamics through the process of facilitation over time. When doing introductions at the beginning of member-check sessions, academic partners shared their names and pronouns and explained their roles as related to the research study and member check session, rather than by titles or positions. When we began meeting for the Expectations to Change process, all members in the advisory group contributed to the development of group guidelines (Adams et al., 2015). Academic partners emphasized that group guidelines applied to everyone in the group, including themselves.

The shifting of power was also reflected in the loosening of boundaries over time, particularly around self-disclosure by academic partners. More rigid boundaries around their self-disclosure existed during the data collection phase of the study, as well as during member checks. However, once the advisory group began, academic partners increased their self-disclosure - as did community partners - which we believe facilitated the deepening of relationships and building authentic connections. Self-disclosure from academic partners may have also served to attenuate the researcher-participant hierarchy (Muhammad et al., 2015); self-disclosure is considered a tool to reduce power imbalances in therapy relationships (Conlin, 2017).

While the academic partners take on the bulk of logistical responsibilities such as coordinating advisory group meetings, the idea generation and decision-making is done as a group. In addition, the group has moved toward consensus decision-making in order to more formally share power and enact a democratic process emblematic of participatory processes. Consensus decisionmaking is a process of idea generation, open discussion, and collective decisionmaking in which all parties are in agreement before the group can proceed. Members can either allow a decision to proceed by actively supporting it or by remaining neutral and not blocking the decision from proceeding forward. If even one member is in disagreement of the decision moving forward, the group continues the conversation until agreement can be reached (Seeds for Change, 2010).

As members have continued to introduce ideas into the group through a shared decision-making process, academic partners periodically initiate conversations to check in on process and acknowledge power dynamics in an effort to model transparency, create space for the group to raise critiques or concerns, and affirm each person's distinct expertise. Community partners have also shared with transparency, honestly asserting their perspectives, desires and preferences. During one of these process check-ins, a member who has experienced harm brought up the idea to produce a podcast to share information with a wider group of IPV survivors. Her leadership contributed 
to a shift in the direction of the group, whereby we have moved toward the production of a podcast and put the community-based advocacy intervention on hold.

\section{Tensions in Shifting and Sharing Power}

Despite the shift to increased collaboration and shared decision-making within the advisory group, implicit power dynamics persist and continue to be actively challenged and disrupted. For instance, one community partner asserted that we could not start the meeting without the PI of the needs assessment study, who had not yet joined. Once the PI joined, she affirmed that meetings can and should continue without her, explicitly stating that all members' contributions are equal, and one does not hold more weight than the other.

Navigating Logistics and Group Planning. Another tension we encountered was working on sharing power equitably amongst the group while also responding to the differing capacities and needs of all group members. Academic partners have taken the lead on maintaining the structure and logistics for the group - coordinating and scheduling meetings, maintaining notes, developing agendas based on discussion in the previous meeting, and facilitating meetings to help the group stay on track with intended discussion items. Community partners have asserted that having the academic partners provide the infrastructure helps to engage with the group in ways that are feasible for them. One community partner shared that, given her busy schedule, she appreciates when others can take the lead on logistics. Another community partner shared that taking on a leadership role would have overwhelmed her because she was still learning about IPV.

However, academic partners experience structuring group processes as a tension because of the power inherent in this act (Goodman et al., 2017). When academic partners raised this as a tension point, community partners initially disagreed that academic partners taking on logistical responsibilities reflected a power dynamic. However, further discussion revealed that community partners interpreted the term power dynamic as conveying a dynamic of harm, in which they were not being respected or supported. This realization emphasized the importance of developing a shared understanding of power and how power manifests through roles and responsibilities within the group. Once we reached a shared understanding of power, community partners agreed that academic partners leading these responsibilities reflected a power dynamic and simultaneously experienced the distribution of responsibility as facilitative of their participation. Specifically, one community partner generated a metaphor of players being invited to a coaches' meeting to parallel community partners being invited to participate in the Expectations to Change process. However, once the process was complete and the advisory group was established, "players" were not socialized into serving as coaches rather than players. The community partner suggested that academic and 
community partners should co-develop a set of roles and responsibilities when establishing an advisory group to facilitate this socialization process and increase equitable participation.

While community partners experienced the provision of infrastructure and logistical support by academic partners as supportive and facilitative of participatory engagement, we recognize that this may not be the case for all groups. Our group continues to grapple with how academic partners leading group infrastructure perpetuates power imbalances and work to identify ways to redistribute power more equitably. For instance, we have identified several roles that members can take on in each meeting, such as facilitator(s) and scribe, and outlined the responsibilities associated with each role. We believe that rotating these roles facilitates sharing responsibilities more equitably while also not placing the burden of any particular role on one person or set of partners beyond their capacity and interest.

Data Ownership. In addition, the academic partners experience tension by noting the points of departure of this process from traditional CBPR projects. The academic partners' approach to conducting a needs assessment to establish connections with potential community partners is novel. Thus, the original research study is still perceived as owned by the study's PI, whereas any products of the advisory group and its process should be considered products of all group members. In addition, community partners have stated that they see themselves as generating ideas for "how to change the world."

Deepening Participatory Practice. Finally, some academic partners question whether this research process sufficiently comprises participatory practice. They have engaged in constant reflexivity and conversation with one another to increase alignment with CBPR principles. It has helped to consider participatory engagement on a spectrum. For instance, Chung and Lounsbury's (2006) Participation Continuum states that community participation increases as: decision-making power between academic partners and community partners is equalized, ownership of the study shifts from just academic partners to shared ownership, and academic partners move from listening to community partners' concerns toward both parties making collaborative decisions that reflect shared study goals. The original needs assessment study reflects components of "mutual consultation," in which participants' perspectives are integrated into some aspects of the research process, but academic partners retain control of the study. However, participants' recommendations led to the planning of a community-based dissemination project over which there is shared ownership and equal power in decision-making, reflecting elements of "empowered co-investigation" (Chung \& Lounsbury, 2006).

\section{Principle 4: Bidirectional Learning}

Bidirectional learning involves the mutual exchange of knowledge between academic and community partners. It is a critical component of participatory approaches due to the neglected and oft-dismissed expertise of community partners $-a$ result of structural oppression embedded within traditional 
research methods (Ghanbarpour et al., 2018). Thus, participatory methods require that opportunities be established for both parties to learn from one another (Ghanbarpour et al., 2018; Goodman et al., 2017). Many examples of bidirectional learning in our process have been mentioned above. The very nature of the needs assessment and member check sessions were designed to provide a platform where academic partners can learn from IPV survivors. In the advisory group, academic partners have shared knowledge on power, privilege, and oppression and how these forces influence IPV survivors, which is a means by which to promote critical consciousness development (Diemer et al., 2016; McGirr \& Sullivan, 2017).

Further, academic partners facilitated a "Domestic Violence (DV) 101," during which all group members shared their perspectives on the training content. For example, academic partners discussed two approaches to DV work - the family violence approach and feminist approaches (Weldon \& Gilchrest, 2012). While academic partners acknowledged that the latter guided their research work, one community partner asserted that she aligned more with the family violence approach and that she did not like the term "feminism." We discussed whether we could reach an agreement on the values that would guide us through the process of establishing a community-based dissemination project. Established values included "respect," "autonomy," and "inclusion," which signified making room for people who have experienced harm with diverse identities, as well as affirming that there is no right way to survive violence. Once agreement was reached, the group moved forward with planning the community-based dissemination project.

Academic partners have also learned a tremendous amount from community partners. Community partners have shared critical information around how people who have experienced harm negotiate tensions related to exposure when still with their partners and simultaneously working to contribute to making change to support others who experience harm. In addition, the community partner who proposed hosting a podcast opened new space to contribute their talents and skills in envisioning implementing the podcast. One community partner invited someone from her personal network to join a meeting to share some of his expertise in planning and executing recordings. Similarly, another community partner contributed her expertise in marketing and promotion for corporate entities to the development of the podcast. Academic partners knew little about podcasts and have followed the community partners' leads.

\section{Tensions in Bidirectional Learning}

Tensions around engaging in bidirectional learning relate to the persistence of implicit power dynamics. Academic partners have facilitated workshopstyle sessions on domestic violence, power and control, and approaches to relationship violence intervention. One community partner stated that she learned about IPV and dynamics of power and control from being in the advisory group. This dynamic can perpetuate the assumption that academic partners have "more" knowledge than community partners — an assumption 
rooted in the power and privilege that comes with being associated with academic institutions (Muhammad et al., 2015). The academic partners have aimed to combat this dynamic by continually emphasizing and valuing the expertise of community members. Academic partners continue to name our guiding value - there is no one right way to survive violence - therefore affirming that community partners' personal experiences with harm are valid and a critical point of insight to advance the field. However, as a group, we recognize that our efforts to address and combat this tendency require continual work and identification of additional strategies.

\section{Lessons Learned}

This paper outlines concrete strategies to increase participatory engagement with people who have experienced harm whose partners enter a relationship violence intervention program. Pulling from the theoretical underpinnings of survivor-centered, trauma-informed, and CBPR practices, this paper demonstrates strategies and tensions relating to four key principles across all three fields: 1) Being responsive to the unique needs and contexts of those who have experienced harm; 2) Building trust and authentic relationships; 3) Shifting and sharing power; and 4) Bidirectional learning.

\section{Strategies for Engaging Hard-to-Reach Populations}

Engaging vulnerable populations at the outset of a research study can be challenging when they are hard-to-reach. Utilizing a qualitative needs assessment is a method to gain access to a vulnerable population such as IPV survivors while simultaneously exploring their often-understudied needs. Additionally, member checking can serve as an entryway to participatory engagement, increasing participants' ownership over the data and investment in responding to the study's findings, which in turn increases the trustworthiness of the study's findings (Caretta, 2016). Academic partners can also employ a group format to engage in a collaborative data analysis and action planning with community partners (Adams et al., 2015).

When establishing a group, academic partners can be responsive to survivors' needs and contexts by sharing information about what group involvement could look like. Academic partners can also assert their commitment to co-creating opportunities for involvement that prioritize survivors' safety and assess a comfortable level of exposure for each group member. Establishing formal and ongoing feedback loops can also facilitate identifying and responding to survivors' evolving needs, particularly around safety and exposure. In the group format, academic partners can work to shift power dynamics by increasing collaboration and sharing power in the decisionmaking process using strategies such as consensus decision-making (Seeds for Change, 2010). Roles and responsibilities can be co-developed, and roles can be rotated amongst academic and community partners to ensure equitable sharing of power. 
In our process, we believe that incorporating survivor-centered, traumainformed, and CBPR practices - specifically through flexibility, responsiveness, and authentic relationship-building - facilitated a trustbuilding process that increased participatory engagement over time. When community partners were asked what has kept them coming back, they emphasized the desire to make positive change and use their stories to help others in similar situations. Community partners described the advisory group as a way to fulfill their purpose, as well as to share with and learn from others. They also noted that the consistency of academic partners in being flexible and co-creating an accepting, physically and emotionally safe and supportive space, sustained their engagement over time. One community partner said, "[Academic partners] made sure my opinions, safety, mental strength were always a priority. I felt like I was going to make a difference after I left every meeting, that's why I was willing to go participate.” Another community partner shared that she kept coming back because academic partners kept "making room for me, welcoming me, accommodating my tethers; whether it was my state of mind, children, schedule, anything that was tethered to me forming conditions around my participation was welcomed and met with positivity.”

\section{Tensions in the Process of Increasing Participatory Engagement}

There were also numerous tensions we encountered through this process. When establishing the advisory group, academic partners encountered tensions when trying to create a space conducive to open dialogue while also promoting critical consciousness. The group has encountered tensions around language and terminology, as community partners have asserted their desire to be referred to as people who have experienced harm rather than using the term "survivors," which is used in the academic literature. Community partners have also raised concerns about exposure as the advisory group moves toward sharing our process via academic conferences and manuscripts. In addition, the advisory group continues to negotiate the right balance of meeting time to spend on relationship-building versus progressing on agenda items and planning efforts for the community-based dissemination project.

Other tensions surround the degree to which power is equitably shared amongst academic and community partners, as well as the degree to which our process comprises participatory practice. Academic partners continue to grapple with how providing logistical infrastructure for advisory group meetings perpetuates power imbalances. Implicit power dynamics persist and need to be continually challenged, particularly by academic partners. Power imbalances may also show up through implicit privileging of knowledge and experiences shared by academic partners.

According to the Chung and Lounsbury's (2006) Participation Continuum, the advisory group involves elements of "empowered coinvestigation" based on shared ownership of the process and its products, as well as equal power in decision-making. We believe that embodying some elements of "empowered co-investigation" can potentially lead to full 
embodiment of "empowered co-investigation" should the advisory group coconceptualize and co-design a research study in the future. However, our current process is guided by the shared group's interests, strengths, and capacities, rather than academic partners prioritizing a research agenda that may disproportionately benefit them. We hope that this is a form of attenuating power - an organic movement through the process and reliance on authentic relationships rather than steering the direction of the group in some way. Additionally, we see value in incorporating participatory engagement practices at all stages of the continuum. Thus, we encourage other researchers to be creative around how to increase participatory engagement in their respective projects.

In conclusion, we urge researchers who work with vulnerable populations to incorporate survivor-centered, trauma-informed, and participatory practices into their work in order to build trust and develop relationships that serve as a foundation for beginning the process of participatory engagement toward the goal of "empowered co-investigation" (Chung \& Lounsbury, 2006). In addition, academic partners should bring intention and creativity to the selection of participatory research methods to engage community partners (Vaughn \& Jacquez, 2020). Establishing an advisory group in which academic partners collaboratively participate is one such way to initiate participatory engagement and prioritize trust- and relationship-building as cornerstones of increasing participatory engagement in the research process over time. Active check-ins, ongoing feedback loops, and consensus decision-making are additional strategies to be responsive to people's needs and contexts, continue deepening relationships, and to share power equitably. 


\section{REFERENCES}

Adams, A., Nnawulezi, N., \& Vandenberg, L. (2015). "Expectations to change” (E2C): A participatory method for facilitating stakeholder engagement with evaluation findings. American Journal of Evaluation, 36(2), 243-255. https://doi.org/10.1177/1098214014553787

Andrews, N. C. Z., Pepler, D. J., \& Motz, M. (2019). Research and Evaluation with CommunityBased Projects: Approaches, Considerations, and Strategies. American Journal of Evaluation, 40(4), 548-561. https://doi.org/10.1177/1098214019835821

Bennett Cattaneo, L., \& Goodman, L. (2010). Through the lens of therapeutic jurisprudence: The relationship between empowerment in the court system and well-being for intimate partner violence victims. Journal of Interpersonal Violence, 25, 481-502. https://doi.org/10.1177/ $\underline{0886260509334282}$

Billoux, S., Arbus, C., Telmon, N., \& Voltzenlogel, V. (2016). Autobiographical memory impairment in female victims of intimate partner violence. Journal of Family Violence, 31(7), 897-902. https://doi.org/10.1007/s10896-016-9838-7

Birt, L., Scott, S., Cavers, D., Campbell, C., \& Walter, F. (2016). Member checking: A tool to enhance trustworthiness or merely a nod to validation? Qualitative Health Research, 26(13), 1802-1811. https://doi.org/10.1177/1049732316654870

Braun, V., Clarke, V., Hayfield, N., \& Terry, G. (2019). Thematic analysis. In P. Liamputtong (Ed.), Handbook of Research Methods in Health Social Sciences (pp. 843-860). https://doi.org/10.1007/ 978-981-10-2779-6 103-1

Brooks, A., \& Hesse-Biber, S. N. (2007). An invitation to feminist research. In S. N. Hesse-Biber (Ed.), Feminist research practice: A primer (1st ed., pp. 1-24). SAGE Publications, Inc. https://doi.org/10.4135/9781412984270.n1

Caretta, M. A. (2016). Member checking: A feminist participatory analysis of the use of preliminary results pamphlets in cross-cultural, cross-language research. Qualitative Research, 16(3), 305-318. https://doi.org/10.1177/1468794115606495

Christopher, S., Watts, V., McCormick, A., \& Young, S. (2008). Building and Maintaining Trust in a Community-Based Participatory Research Partnership. American Journal of Public Health, 98(8), 1398-1406. https://doi.org/10.2105/ajph.2007.125757

Chung, K., \& Lounsbury, D. W. (2006). The role of power, process, and relationships in participatory research for statewide HIV/AIDS programming. Social Science E̊ Medicine, 63(8), 2129-2140. https://doi.org/10.1016/j.socscimed.2006.04.035

Collins, S. E., Clifasefi, S. L., Stanton, J., The LEAP Advisory Board, Straits, K. J., Gil-Kashiwabara, E., Rodriguez Espinosa, P., Nicasio, A. V., Andrasik, M. P., Hawes, S. M., Miller, K. A., Nelson, L. A., Orfaly, V. E., Duran, B. M., \& Wallerstein, N. (2018). Community-based participatory research (CBPR): Towards equitable involvement of community in psychology research. American Psychologist, 73(7), 884-898. https://doi.org/10.1037/amp0000167

Conlin, S. E. (2017). Feminist therapy: A brief integrative review of theory, empirical support, and call for new directions. Women's Studies International Forum, 62, 78-82. https://doi.org/10.1016/ j.wsif.2017.04.0020277-5395

Creswell, J. W., \& Miller, D. L. (2000). Determining validity in qualitative inquiry. Theory into Practice, 39(3), 124-130. https://doi.org/10.1207/s15430421tip3903_2

D’Alonzo, K. T. (2010). Getting started in CBPR-Lessons in building community partnerships for new researchers. Nursing Inquiry, 17(4), 282-288. https://doi.org/10.1111/ j.1440-1800.2010.00510.x 
Diemer, M. A., Rapa, L. J., Voight, A. M., \& McWhirter, E. H. (2016). Critical Consciousness: A Developmental Approach to Addressing Marginalization and Oppression. Child Development Perspectives, 10(4), 216-221. https://doi.org/10.1111/cdep.12193

Dillon, G., Hussain, R., Loxton, D., \& Rahman, S. (2013). Mental and physical health and intimate partner violence against women: A review of the literature. International Journal of Family Medicine, 1-15. https://doi.org/10.1155/2013/313909

Duran, B., Wallerstein, N., Avila, M. M., Belone, L., Minkler, M., \& Foley, K. (2012). Developing and maintaining partnerships with communities. In B. A. Israel, E. Eng, A. J. Shultz, \& E. A. Parker (Eds.), Methods for Community-Based Participatory Research for Health (2nd ed., pp. 43-68). Jossey-Bass.

Ghanbarpour, S., Palotai, A., Kim, M. E., Aguilar, A., Flores, J., Hodson, A., Holcomb, T., Jimenez, M., Kaur, M., Pusey, O., Rosales, A., Schlater, W., \& Shim, H. (2018). An Exploratory Framework for Community-Led Research to Address Intimate Partner Violence: A Case Study of the SurvivorCentered Advocacy Project. Journal of Family Violence, 33(8), 521-535. https://doi.org/10.1007/ $\underline{\text { s10896-018-9987-y }}$

Goodman, L. A., Thomas, K. A., Serrata, J. V., Lippy, C., Nnawulezi, N., Ghanbarpour, S., Macy, R., Sullivan, C., \& Bair-Merritt, M. A. (2017). Power through partnerships: A CBPR toolkit for domestic violence researchers. National Resource Center on Domestic Violence. https://cbprtoolkit.org

Goodman, L. A., Thomas, K., Cattaneo, L. B., Heimel, D., Woulfe, J., \& Chong, S. K. (2016). Survivor-defined practice in domestic violence work: Measure development and preliminary evidence of link to empowerment. Journal of Interpersonal Violence, 31(1), 163-185. https://doi.org/10.1177/0886260514555131

Israel, B. A., Schulz, A. J., Parker, E. A., \& Becker, A. B. (2008). Critical Issues in Developing and Following Community-Based Participatory Research Principles. In N. Wallerstein, B. Duran, J. G. Oetzel, \& M. Minkler (Eds.), Community-based participatory research for health: Advancing social and health equity (pp. 47-62). Jossey-Bass.

Kubiak, S. P., Nnawulezi, N., Karim, N., Sullivan, C. M., \& Beeble, M. L. (2012). Examining rates of disclosure on questions of physical and sexual violence by method in samples of women involved in the criminal justice system. Journal of Offender Rehabilitation, 51(3), 161-175. https://doi.org/ $\underline{10.1080 / 10509674.2011 .618528}$

Lincoln, Y. S., \& Guba, E. G. (1985). Establishing trustworthiness. In Y. S. Lincoln \& E. G. Guba (Eds.), Naturalistic inquiry (pp. 289-331). SAGE Publishing. https://doi.org/10.1016/ $\underline{0147-1767(85) 90062-8}$

Lucero, J. E., Boursaw, B., Eder, M., Greene-Moton, E., Wallerstein, N., \& Oetzel, J. G. (2020). Engage for Equity: The Role of Trust and Synergy in Community-Based Participatory Research. Health Education Eg Behavior, 47(3), 372-379. https://doi.org/10.1177/1090198120918838

Macy, R. J., Giattina, M. C., Montijo, N. J., \& Ermentrout, D. M. (2010). Domestic Violence and Sexual Assault Agency Directors' Perspectives on Services That Help Survivors. Violence Against Women, 16(10), 1138-1161. https://doi.org/10.1177/1077801210383085

McGirr, S. A., \& Sullivan, C. M. (2017). Critical Consciousness Raising as an Element of Empowering Practice with Survivors of Domestic Violence. Journal of Social Service Research, 43(2), 156-168. https://doi.org/10.1080/01488376.2016.1212777

Menschner, C., \& Maul, A. (2016). Key ingredients for successful trauma-informed care implementation. Center for Health Care Strategies, Incorporated. https:/www.traumainformedcare.chcs.org/wp-content/uploads/2018/11/Brief-Key-Ingredientsfor-TIC-Implementation.pdf 
Miles, M. B., Huberman, A. M., \& Saldaña, J. (2014). Fundamentals of Qualitative Data Analysis. In Qualitative data analysis: A methods sourcebook (3rd ed., pp. 69-104). SAGE Publishing.

Muhammad, M., Wallerstein, N., Sussman, A. L., Avila, M., Belone, L., \& Duran, B. (2015). Reflections on Researcher Identity and Power: The impact of positionality on community-based participatory research (CBPR) processes and outcomes. Critical Sociology, 41(7-8), 1045-1063. https://doi.org/10.1177/0896920513516025

Nichols, A. J. (2013). Survivor-defined practices to mitigate revictimization of battered women in the protective order process. Journal of Interpersonal Violence, 28(7), 1403-1423. https://doi.org/ $10.1177 / 0886260512468243$

Nnawulezi, N., Lippy, C., Serrata, J., \& Rodriguez, R. (2018). Doing equitable work in inequitable conditions: A special issue on transformative research methods in the gender-based violence field. Journal of Family Violence, 33(8), 507-513. https://doi.org/10.1007/s10896-018-9998-8

Nnawulezi, N., \& Murphy, C. (2019). Understanding formal help-seeking among women whose partners are in abuser treatment programs. Psychology of Violence, 9(4), 383-391. https://doi.org/ $\underline{10.1037 / \text { vio0000126 }}$

Ragavan, M. I., Thomas, K. A., Fulambarker, A., Zaricor, J., Goodman, L. A., \& Bair-Merritt, M. H. (2020). Exploring the Needs and Lived Experiences of Racial and Ethnic Minority Domestic Violence Survivors Through Community-Based Participatory Research: A Systematic Review. Trauma, Violence, E Abuse, 21(5), 946-963. https://doi.org/10.1177/1524838018813204

Seeds for Change. (2010). Consensus decision-making. Seeds for Change: Strengthening Cooperation, Empowering Resistance. https://www.seedsforchange.org.uk/consensus.pdf

Smith, S. G., Zhang, X., Basile, K. C., Merrick, M. T., Wang, J., Kresnow, M., \& Chen, J. (2018). The national intimate partner and sexual violence survey (NISVS): 2015 Data brief - Updated release. National Center for Injury Prevention and Control, Centers for Disease Control and Prevention. https://www.cdc.gov/violenceprevention/pdf/NISVS-StateReportBook.pdf

Stark, E. (2007). Coercive control: How men entrap women in personal life (1st ed.). Oxford University Press.

Substance Abuse and Mental Health Services Administration. (2014). SAMHSA's concept of trauma and guidance for a trauma-informed approach (HHS Publication [SMA] 14-4884).

Vaughn, L. M., \& Jacquez, F. (2020). Participatory research methods - Choice points in the research process. Journal of Participatory Research Methods, 1(1), 13244-13258. https://doi.org/10.35844/ $\underline{001 c .13244}$

Wallerstein, N., \& Duran, B. (2017). The theoretical, historical and practice roots of CBPR. In N. Wallerstein, B. Duran, J. G. Oetzel, \& M. Minkler (Eds.), Community-based participatory research for health: Advancing social and health equity (pp. 17-29). Jossey-Bass.

Weldon, S., \& Gilchrest, E. (2012). Implicit Theories in Intimate Partner Violence Offenders. Journal of Family Violence, 27, 761-772. https://doi.org/10.1007/s10896-012-9465-x

Wilson, J. M., Fauci, J. E., \& Goodman, L. A. (2015). Bringing Trauma-Informed Practice to Domestic Violence Programs: A Qualitative Analysis of Current Approaches. American Journal of Orthopsychiatry, 85(6), 586-599. https://doi.org/10.1037/ort0000098 